\title{
An improved coupling model for water flow, sediment transport and bed evolution (CASFE v.1)
}

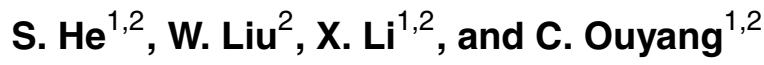

${ }^{1}$ Key laboratory of Mountain Hazards and Earth Surface Process, Chinese Academy of Science, Chengdu, China

${ }^{2}$ Institute of Mountain Hazards and Environment (IMHE), Chinese Academy of Sciences, Chengdu, China

Received: 18 December 2013 - Accepted: 20 March 2014 - Published: 11 April 2014

Correspondence to: X. Li (lixinpo@imde.ac.cn)

Published by Copernicus Publications on behalf of the European Geosciences Union.

An improved erosion model for surface flows

S. He et al.

Title Page

Abstract Introduction

Conclusions References

Tables Figures

14 I

4

Back

Close

Full Screen / Esc

Printer-friendly Version

Interactive Discussion

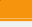




\section{Abstract}

This paper presents a new coupling model to simulate water flow, sediment transport and bed evolution based on the shallow water assumption, depth-average integration as well as the morphological evolution (Chinese Academy of Sciences flow-erosion 5 model, CASFE). The model takes account of the effects of rainfall, entrainment and deposition on the motion of water-sediment mixtures. Limitations and drawbacks of other authors' models are pointed out according to the comparison among these models. The finite volume method has been adopted to solve the one-dimensional dam-break problem considering an erodible bed. Numerical results indicate that the model can adequately describe the complex dynamic problems. Simulation results demonstrate that the entrainment and deposition significantly affects the flow dynamics and morphological evolution.

\section{Introduction}

In recent years, the catastrophic flood events in worldwide are increasingly frequent and its dynamics mechanism has attracted much interest as how to predict it by numerical method. It is generally accepted that reliable methods for predicting the water flow, sediment transport and bed evolution can play important role in development of control strategy for environmental protection. The mathematical models are considered to be one of the best ways for understanding the dynamics of water flow and sediment transport. In the past decades, numerical solutions, including finite element method, finite volume method and finite difference method, are mainly focused on the shallow water equations related with mass movement over a fixed bed. Nevertheless, in order to exhibit the geomorphological evolution, it is necessary to couple the shallow water equations describing the flow continuity and the momentum conservation equation, the sediment continuity equation and the bathymetry evolution equation. Thus, increasing attention is being paid to methods of solving the complete coupled
GMDD

An improved erosion model for surface flows

S. He et al.

Title Page

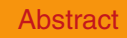

Introduction

Conclusions

Tables

References

Figures

14

$\rightarrow$

4

Back

Close

\section{Full Screen / Esc}

Printer-friendly Version

Interactive Discussion 
equations. A discontinuous Galerkin finite element method (FEM) was implemented to represent the morphodynamic procedure by accounting for the sediment transport and bed evolution (Tassi et al., 2008). In addition, Cao (Cao et al., 2004) presents a one-dimensional dam-break model considering erodible sediment beds. The model 5 used a weighted average flux method and the HLLC approximate Riemann solver with high-order accuracy promoted by SUPERBEE limiter. Many scholars (Fraccarollo et al., 2002; Benkhaldounet al., 2011; Murillo and García-Navarro, 2010; Simpson and Castelltort, 2006) used finite volume method (FVM) to solve the coupled model of water flow, sediment transport and bed evolution.

10 In this paper, a new mathematical model has been presented. This model enables predicting the change of water surface morphology and bed morphology in the time and space through water flow and sediment transport dynamics. The model presented in this study includes the shallow water equations for surface flow, conservation of sediment concentration, substrate erosion and deposition as well as morphodynamics models. In recent years, researches on models coupled sediment transport and water flow without interruption have been provided by Fagherazzi and Sun (2003), Cao et al. (2004, 2006), Simpson et al. (2006), Hu et al. (2009), Schippa et al. (2009), Benkhaldoun et al. (2011), and Li et al. (2011). The model here differs from these in that it takes account of the effect of rainfall, entrainment and deposition on

equation. The equations of the model are hyperbolic and conform to conservation laws. So far, the numerical schemes developed for solving hydrodynamics and morphodynamics problem are matured and the finite volume methods has been adopted for numerical simulation in this study.

This paper is organized as follows. The governing equations for couple model of water flow, sediment transport and bed evolution are presented in Sect. 2. The boundary kinematic condition is formulated in Sect. 3. The depth-integrated equations and the full model equations are derived in Sects. 4 and 5.The comparisons between the present model and the previous models are given in Sect. 6 . The numerical results
GMDD

7, 2429-2454, 2014
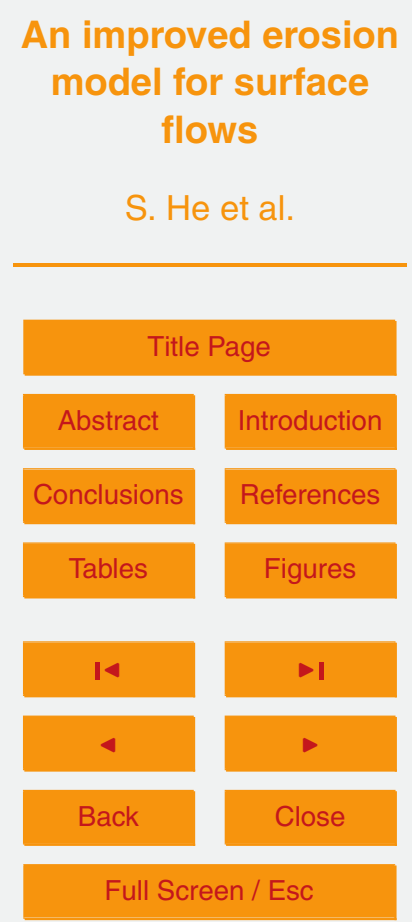

Printer-friendly Version

Interactive Discussion 
and examples are displayed in Sect. 7. At last, Sect. 8 summarizes the concluding remarks.

\section{Model descriptions}

\subsection{Governing equations}

5 The water-sediment mixture is assumed to be an incompressible material with variable density throughout the entire body. Then the mass and momentum conservation laws can be written as

$$
\left.\begin{array}{l}
\frac{\partial \rho}{\partial t}+\nabla \cdot \rho \mathbf{U}=0 \\
\rho\left(\partial_{t} \mathbf{U}+\mathbf{U} \cdot \nabla \mathbf{U}\right)=\rho \mathbf{g}-\nabla \cdot \mathbf{T}
\end{array}\right\}
$$

10 where $\nabla$ is the gradient operator, $t$ is time, $\rho$ is the constant density of water-sediment mixture, $\mathbf{U}$ is the velocity fields, $\mathbf{T}$ is the Cauchy stress tensor, and $\mathbf{g}=(0,0, g)$ is the gravitational acceleration. The analysis employs a Cartesian coordinate system in which $x$ points in the down-slope direction, $y$ points in the cross-slope direction, and $z$ points upward, normal to the slope (see Fig. 1). Equation (1) can be written explicitly 15 on components

$$
\left.\begin{array}{l}
\frac{\partial \rho}{\partial t}+\frac{\partial(\rho u)}{\partial x}+\frac{\partial(\rho v)}{\partial y}+\frac{\partial(\rho w)}{\partial z}=0 \\
\frac{\partial(\rho u)}{\partial t}+\frac{\partial\left(\rho u^{2}\right)}{\partial x}+\frac{\partial(\rho u v)}{\partial y}+\frac{\partial(\rho u w)}{\partial z}=-\left(\frac{\partial \tau_{x x}}{\partial x}+\frac{\partial \tau_{x y}}{\partial y}+\frac{\partial \tau_{x z}}{\partial z}\right) \\
\frac{\partial(\rho v)}{\partial t}+\frac{\partial(\rho u v)}{\partial x}+\frac{\partial\left(\rho v^{2}\right)}{\partial y}+\frac{\partial(\rho v w)}{\partial z}=-\left(\frac{\partial \tau_{x y}}{\partial x}+\frac{\partial \tau_{y y}}{\partial y}+\frac{\partial \tau_{y z}}{\partial z}\right) \\
\frac{\partial(\rho w)}{\partial t}+\frac{\partial(\rho u w)}{\partial x}+\frac{\partial(\rho v w)}{\partial y}+\frac{\partial\left(\rho w^{2}\right)}{\partial z}=\rho g-\left(\frac{\partial \tau_{x z}}{\partial x}+\frac{\partial \tau_{y z}}{\partial y}+\frac{\partial \tau_{z z}}{\partial z}\right)
\end{array}\right\}
$$

An improved erosion model for surface flows

S. He et al.

\section{Title Page}

Abstract Introduction

Conclusions References

Tables Figures

14 $\rightarrow 1$

4

Back

Close

where $u, v$, and $w$ denote Cartesian velocity components in the $x, y$, and $z$ directions. The model assumes that the water-sediment mixture consists of incompressible solid 
grains of mass density $\rho_{\mathrm{s}}$ occupying the volume fraction $c$ mixed with water of mass density $\rho_{\mathrm{w}}$ occupying the volume fraction $1-c$, such that the water-sediment mixture bulk density is

${ }_{5} \rho=\rho_{\mathrm{w}}(1-c)+\rho_{\mathrm{s}} c$

In the process of the water-sediment mixture movement, the water density and solid phase density are constant. However, affected by entrainment and deposition, the solid phase volume fraction changes with time, and so the density of the water-sediment mixture changes with time accordingly.

${ }_{10} \frac{\partial \rho}{\partial t}=\left(\rho_{\mathrm{s}}-\rho_{\mathrm{w}}\right) \frac{\partial c}{\partial t}$

The density of the saturated bed can be expressed as

$\rho_{\mathrm{o}}=\rho_{\mathrm{w}} p+\rho_{\mathrm{s}}(1-p)$

15 where $p$ is bed sediment porosity.

\subsection{Boundary kinematic condition}

The conservation laws Eqs. (1) and (2) are subject to kinematic boundary conditions at the free surface, $z_{\mathrm{t}}(\mathbf{x}, t)=0$, and at the base, $z_{\mathrm{b}}(\mathbf{x}, t)=0$, of the water-sediment mixture (Gray, 2001)

$z_{\mathrm{t}}(\mathbf{x}, t)=0: \frac{\partial z_{\mathrm{t}}}{\partial t}=w_{1}\left(z_{\mathrm{t}}\right)-u_{1}\left(z_{\mathrm{t}}\right) \frac{\partial z_{\mathrm{t}}}{\partial x}-v_{1}\left(z_{\mathrm{t}}\right) \frac{\partial z_{\mathrm{t}}}{\partial y}-R$

$z_{\mathrm{b}}(\mathbf{x}, t)=0: \frac{\partial z_{\mathrm{b}}}{\partial t}=w_{1}\left(z_{\mathrm{b}}\right)-u_{1}\left(z_{\mathrm{b}}\right) \frac{\partial z_{\mathrm{b}}}{\partial x}-v_{1}\left(z_{\mathrm{b}}\right) \frac{\partial z_{\mathrm{b}}}{\partial y}-\frac{E-D}{1-p}$

where the superscripts " $\mathrm{t}$ " and "b" indicate that a variable is evaluated at the surface and base, respectively, $R$ is the rainfall rate, $E, D$ represent the substrate entrainment
GMDD

7, 2429-2454, 2014

An improved erosion

model for surface

flows

S. He et al.

Title Page

Abstract

Introduction

Conclusions

References

Tables

Figures

14

$\rightarrow 1$

4

Back

Close

Full Screen / Esc

Printer-friendly Version

Interactive Discussion 
The difference between the free surface and the base defines the water-sediment mixture thickness

$h=z_{\mathrm{t}}-z_{\mathrm{b}}$

5 The free surface of the debris-flows is traction free, that is

$z_{\mathrm{t}}(\mathbf{x}, t)=0: \mathbf{p}_{\mathrm{t}} \mathbf{n}_{\mathrm{t}}=0$

\subsection{Depth-integrated equations}

A key step in further simplifying the equations of motion involves depth averaging to 10 eliminate explicit dependence on $z$ which is the coordinate normal to the bed (Savage and Hutter, 1989; Pitman and Le, 2005).

The depth-averaged solid phase volume fraction, velocities and stress components are defined by

$\bar{c}=\frac{1}{h} \int_{z_{\mathrm{b}}}^{z_{\mathrm{t}}} c \mathrm{~d} z, \quad \bar{u}=\frac{1}{h} \int_{z_{\mathrm{b}}}^{z_{\mathrm{t}}} u \mathrm{~d} z, \quad \bar{v}=\frac{1}{h} \int_{z_{\mathrm{b}}}^{z_{\mathrm{t}}} v \mathrm{~d} z, \quad \bar{\tau}_{i j}=\frac{1}{h} \int_{z_{1}}^{z_{2}} \tau_{i j} \mathrm{~d} z$

We start by integrating the mass balance equation of the water-sediment mixture in the $z$ direction. Using Leibniz' formula to interchange the differentiation and integration operators, we obtain:

$\int_{z_{\mathrm{b}}}^{z_{\mathrm{t}}}\left(\frac{\partial \rho}{\partial t}+\frac{\partial \rho u}{\partial x}+\frac{\partial \rho v}{\partial y}+\frac{\partial \rho w}{\partial z}\right) \mathrm{d} z=\frac{\partial \bar{\rho} h}{\partial t}+\frac{\partial \bar{\rho} h \bar{u}}{\partial x}+\frac{\partial \bar{\rho} h \bar{v}}{\partial y}+\rho\left(z_{\mathrm{t}}\right) R-\rho\left(z_{\mathrm{b}}\right) \frac{E-D}{1-p}=0$

Assuming that $\rho\left(z_{\mathrm{t}}\right)=\bar{\rho}$ and $\rho\left(z_{\mathrm{b}}\right)=\rho_{0}$, Eq. (11) reduces to

$\frac{\partial h}{\partial t}+\frac{\partial h \bar{u}}{\partial x}+\frac{\partial h \bar{v}}{\partial y}=\frac{E-D}{1-p}-R$

An improved erosion model for surface flows

S. He et al.

Title Page

Abstract

Introduction

Conclusions

References

Tables

Figures

14

$\rightarrow 1$

4

Back

Close

Full Screen / Esc

Printer-friendly Version

Interactive Discussion 
The mass balance equation of the solid phase can be written

$\frac{\partial c \rho_{s}}{\partial t}+\frac{\partial c \rho_{s} u}{\partial x}+\frac{\partial c \rho_{s} v}{\partial y}+\frac{\partial c \rho_{s} w}{\partial z}=0$

GMDD

7, 2429-2454, 2014

The density of solid phase is constant, Eq. (15) reduce to

$5 \frac{\partial c}{\partial t}+\frac{\partial c u}{\partial x}+\frac{\partial c v}{\partial y}+\frac{\partial c w}{\partial z}=0$

Integrating the mass balance equation of the solid phase the $z$ direction. Using Leibniz' formula to interchange the differentiation and integration operators, we obtain

$\int_{z_{\mathrm{b}}}^{z_{\mathrm{t}}}\left(\frac{\partial c}{\partial t}+\frac{\partial c u}{\partial x}+\frac{\partial c v}{\partial y}+\frac{\partial c w}{\partial z}\right) \mathrm{d} z=\frac{\partial \bar{c} h}{\partial t}+\frac{\partial \bar{c} h \bar{u}}{\partial x}+\frac{\partial \bar{c} h \bar{v}}{\partial y}+c\left(z_{\mathrm{t}}\right) R-c\left(z_{\mathrm{b}}\right) \frac{E-D}{1-p}=0$

Assuming that $c\left(z_{\mathrm{t}}\right)=\bar{c}$ and $c\left(z_{\mathrm{b}}\right)=1-p$, Eq. (15) reduce to

$\frac{\partial \bar{c} h}{\partial t}+\frac{\partial \bar{c} h \bar{u}}{\partial x}+\frac{\partial \bar{c} h \bar{v}}{\partial y}=E-D-\bar{c} R$

The left-hand side of the $x$ momentum Eq. (2) can be written as

$L H S=\frac{\partial(\rho u)}{\partial t}+\frac{\partial\left(\rho u^{2}\right)}{\partial x}+\frac{\partial(\rho u v)}{\partial y}+\frac{\partial(\rho u w)}{\partial z}$

Title Page

Abstract

Introduction

Conclusions

References

Tables

Figures

14

$\rightarrow$

Full Screen / Esc

Printer-friendly Version 
Depth averaging and using boundary conditions yields

$$
\begin{aligned}
& \int_{z_{\mathrm{b}}}^{z_{\mathrm{t}}} L H S \mathrm{~d} z=\int_{z_{\mathrm{b}}}^{z_{\mathrm{t}}}\left[\frac{\partial(\rho u)}{\partial t}+\frac{\partial\left(\rho u^{2}\right)}{\partial x}+\frac{\partial(\rho u v)}{\partial y}+\frac{\partial(\rho u w)}{\partial z}\right] \mathrm{d} z \\
& \int_{z_{\mathrm{b}}}^{z_{\mathrm{t}}} L H S \mathrm{~d} z=\bar{\rho} \frac{\partial(h \bar{u})}{\partial t}+\frac{\partial\left(h \bar{u}^{2}\right)}{\partial x}+\frac{\partial(h \bar{u} \bar{v})}{\partial y}+\bar{\rho} u\left(z_{\mathrm{t}}\right) R-\rho_{0} u\left(z_{\mathrm{b}}\right) \frac{E-D}{1-p}+\frac{\bar{u}(E-D)\left(\rho_{0}-\rho\right)}{1-p}
\end{aligned}
$$

5 Now, depth averaging the right-hand side of the $x$ momentum Eq. (2) yields

$$
\int_{z_{\mathrm{b}}}^{z_{\mathrm{t}}}(\mathrm{RHS}) \mathrm{d} z=-\frac{\partial\left(h \bar{\tau}_{x x}\right)}{\partial x}-\frac{\partial\left(h \bar{\tau}_{x y}\right)}{\partial y}-\tau_{x x}\left(z_{\mathrm{b}}\right) \frac{\partial z_{\mathrm{b}}}{\partial x}-\tau_{x y}\left(z_{\mathrm{b}}\right) \frac{\partial z_{\mathrm{b}}}{\partial y}-\tau_{x z}\left(z_{\mathrm{b}}\right)
$$

For the water-sediment mixture, shallow water equations is valid (such an assumption can be considered for low concentrations).

$\bar{\tau}_{x x}=\bar{\tau}_{y y}=\bar{\tau}_{z z}=\frac{1}{2} \rho g h$ and $\tau_{x y}=\tau_{y x}=0$

$$
\begin{aligned}
& \int_{z_{\mathrm{b}}}^{z_{\mathrm{t}}}(\mathrm{RHS}) \mathrm{d} z=-\frac{\partial}{\partial x}\left(\frac{1}{2} \bar{\rho} g h^{2}\right)-\bar{\rho} g h \frac{\partial z_{\mathrm{b}}}{\partial x}-g h S_{\mathrm{f} x} \\
& \int_{z_{\mathrm{b}}}^{z_{\mathrm{t}}}(\mathrm{RHS}) \mathrm{d} z=-\bar{\rho} g h \frac{\partial h}{\partial x}-\frac{1}{2}\left(\rho_{s}-\rho_{w}\right) g h^{2} \frac{\partial c}{\partial x}-\bar{\rho} g h \frac{\partial z_{\mathrm{b}}}{\partial x}-g h S_{\mathrm{f} x} \\
& \frac{\partial(h \bar{u})}{\partial t}+\frac{\partial}{\partial x}\left(h \bar{u}^{2}+\frac{1}{2} g h^{2}\right)+\frac{\partial(h \bar{u} \bar{v})}{\partial y}=u\left(z_{\mathrm{b}}\right) \frac{(E-D) \rho_{0}}{(1-p) \bar{\rho}}-u\left(z_{\mathrm{t}}\right) R-\frac{\bar{u}(E-D)\left(\rho_{0}-\rho\right)}{(1-p) \bar{\rho}} \\
& -\frac{\left(\rho_{s}-\rho_{w}\right) g h^{2}}{2 \bar{\rho}} \frac{\partial \bar{c}}{\partial x}-g h\left(\frac{\partial z_{\mathrm{b}}}{\partial x}+S_{\mathrm{f} x}\right)
\end{aligned}
$$

An improved erosion model for surface flows

S. He et al.

Title Page

Abstract Introduction

Conclusions

Tables

References

Figures

14

$\rightarrow 1$

4

Back

Close

Full Screen / Esc

Printer-friendly Version

Interactive Discussion 
The depth-integrated equations for the $y$ momentum component are precisely analogous to those derived above for the $x$ component. Thus, interchanging $x$ and $y$ as well as $u$ and $v$ in the preceding section yields the $y$ component equation

$$
\begin{aligned}
\frac{\partial(h \bar{v})}{\partial t}+\frac{\partial(h \bar{u} \bar{v})}{\partial x}+\frac{\partial}{\partial y}\left(h \bar{v}^{2}+\frac{1}{2} g h^{2}\right)= & v\left(z_{\mathrm{b}}\right) \frac{(E-D) \rho_{0}}{(1-p) \bar{\rho}}-v\left(z_{\mathrm{t}}\right) R-\frac{\bar{u}(E-D)\left(\rho_{0}-\rho\right)}{(1-p) \bar{\rho}} \\
& -\frac{\left(\rho_{s}-\rho_{w}\right) g h^{2}}{2 \bar{\rho}} \frac{\partial \bar{c}}{\partial y}-g h\left(\frac{\partial z_{\mathrm{b}}}{\partial y}+S_{\mathrm{f} y}\right)
\end{aligned}
$$

The relations between the friction slope and the substrate exchange fluxes are needed to close the governing equations at the boundary. According to the different conditions, different friction slope equations can be selected and the Darcy-Weisbach equation is considered to approximate the overland flow in our model:

${ }_{10} S_{\mathrm{f} x}=\frac{f \bar{u} \sqrt{\bar{u}^{2}+\bar{v}^{2}}}{8 g h}, \quad S_{\mathrm{f} y}=\frac{f \bar{v} \sqrt{\bar{u}^{2}+\bar{v}^{2}}}{8 g h}$

where $f$ is the Darcy-Weisbach friction factor depends on the Reynolds number. In this paper we consider $f$ as a constant. $D$ and $E$ represent the sediment deposition and entrainment fluxes across the surface between the flow and the bed. $p$ is the bed sediment porosity. According to the previous works (Benkhaldoun et al., 2011; Cao et al., 2004), $D$ and $E$ can be expressed as

$D=\omega_{0}\left(1-C_{\alpha}\right)^{m} C_{\alpha}$

$E= \begin{cases}\phi\left(\theta-\theta_{\mathrm{c}}\right) \sqrt{u^{2}+v^{2}} h^{-1} d^{-0.2} & \text { if } \theta \geq \theta_{\mathrm{c}} \\ 0 & \text { else }\end{cases}$

where $\omega_{0}$ is a parameter represent the velocity when a single particle settle in tranquil water, which is expressed as

$\omega_{0}=\sqrt{\left(13.95 \frac{U}{d}\right)^{2}+1.09 s g d}-13.95 \frac{v}{d}$
GMDD

7, 2429-2454, 2014

An improved erosion model for surface

flows

S. He et al.

Title Page

Abstract

Introduction

Conclusions

References

Tables

Figures

14

$\rightarrow$ I

4

Back

Close

Full Screen / Esc

Printer-friendly Version

Interactive Discussion 
$C_{\alpha}=c \alpha_{\mathrm{c}}$ is the near-bed volumetric sediment concentration and $\alpha_{\mathrm{c}}$ can be obtained by $\alpha_{\mathrm{c}}=\min (2,(1-p) / c), v$ is the water kinematic viscosity, $d$ is the grain diameter, $m$ is an exponent, $\phi$ is a coefficient about the erosion forces, $\theta_{c}$ is a critical value of Shields parameter determining the initiation of sediment motion, $\theta=u^{*} /(s g d)$ is

5 Shields parameter, $u^{*}=\sqrt{g h S_{f}}$ is the friction velocity, $s=\rho_{s} / \rho_{w}-1$ is the submerged specific gravity of sediment.

To show the change of bed-load, the conservation law of the sediment is described by the Exner equation (Murillo et al., 2010; Li et al., 2011)

$\frac{\partial z_{\mathrm{b}}}{\partial t}=-\frac{E-D}{1-p}$

\subsection{The full model equations}

The complete sets of model equations are rewritten here. To simplify notation, hats and over-bars are dropped.

$$
\left.\begin{array}{ll}
\frac{\partial h}{\partial t}+\frac{\partial h u}{\partial x}+\frac{\partial h v}{\partial y}=\frac{E-D}{1-p}-R & \\
\frac{\partial c h}{\partial t}+\frac{\partial c h u}{\partial x}+\frac{\partial c h v}{\partial y}=E-D-c R & \\
\frac{\partial(h u)}{\partial t}+\frac{\partial}{\partial x}\left(h u^{2}+\frac{1}{2} g h^{2}\right)+\frac{\partial(h u v)}{\partial y}= & u\left(z_{\mathrm{b}}\right) \frac{(E-D) \rho_{0}}{(1-p) \rho}-u\left(z_{\mathrm{t}}\right) R-\frac{u(E-D)\left(\rho_{0}-\rho\right)}{(1-p) \rho} \\
& -\frac{\left(\rho_{s}-\rho_{w}\right) g h^{2}}{2 \bar{\rho}} \frac{\partial c}{\partial x}-g h\left(\frac{\partial z_{\mathrm{b}}}{\partial x}+S_{\mathrm{f} x}\right) \\
\frac{\partial(h v)}{\partial t}+\frac{\partial(h u v)}{\partial x}+\frac{\partial}{\partial y}\left(h v^{2}+\frac{1}{2} g h^{2}\right)= & v\left(z_{\mathrm{b}}\right) \frac{(E-D) \rho_{0}}{(1-p) \rho}-v\left(z_{\mathrm{t}}\right) R-\frac{u(E-D)\left(\rho_{0}-\rho\right)}{(1-p) \rho} \\
& -\frac{\left(\rho_{s}-\rho_{w}\right) g h^{2}}{2 \bar{\rho}} \frac{\partial c}{\partial y}-g h\left(\frac{\partial z_{\mathrm{b}}}{\partial y}+S_{\mathrm{f} y}\right) \\
\frac{\partial z_{\mathrm{b}}}{\partial t}=-\frac{E-D}{1-p} &
\end{array}\right\}
$$

The model Eq. (26) constitutes a system of five equations in the variables $h(x, y, t)$, $u(x, y, t), v(x, y, t), c(x, y, t), z_{\mathrm{b}}(x, y, t)$. Together with initial and boundary conditions, the system constitutes a well-posed set of equations describing a water flow, sediment transport and bed evolution system.

An improved erosion model for surface flows

S. He et al.

Title Page

Abstract Introduction

Conclusions References

Tables Figures

14 $\rightarrow 1$

4

Back

Close

Full Screen / Esc

Printer-friendly Version

Interactive Discussion 


\subsection{Discussions}

In this paper, based on the shallow water equations, coupled the water flow, sediment transport and bed evolution, to constitute a system model Eq. (26). Equation (26) differs from the conservation equations used in many previous models of the shallow water

5 flow, sediment transport and bed evolution as summarized in Table 1.

\section{Computational scheme}

In this study, the numerical method chosen to solve Eq. (26) is a finite volume approach which is well suited for transient problems involving erosion and deposition of sediments, and is briefly outlined below. Rainfall is currently not considered in this numerical test, and so Eq. (26) can be reduced as follows

$$
\left.\begin{array}{l}
\frac{\partial h}{\partial t}+\frac{\partial h u}{\partial x}=\frac{E-D}{1-p} \\
\frac{\partial c h}{\partial t}+\frac{\partial c h u}{\partial x}=E-D \\
\frac{\partial(h u)}{\partial t}+\frac{\partial}{\partial x}\left(h u^{2}+\frac{1}{2} g h^{2}\right)=u\left(z_{\mathrm{b}}\right) \frac{(E-D) \rho_{0}}{(1-p) \rho}-u\left(z_{\mathrm{t}}\right) R- \\
\frac{u(E-D)\left(\rho_{0}-\rho\right)}{(1-p) \rho}-\frac{\left(\rho_{s}-\rho_{w}\right) g h^{2}}{2 \bar{\rho}} \frac{\partial c}{\partial x}-g h\left(\frac{\partial z_{\mathrm{b}}}{\partial x}+S_{\mathrm{fx}}\right) \\
\frac{\partial z_{\mathrm{b}}}{\partial t}=-\frac{E-D}{1-p}
\end{array}\right\}
$$

In order to provide a reasonably compact presentation of the numerical scheme, it is useful to cast Eq. (27) in a more abstract form in vector format as follows

${ }_{15} \frac{\partial U}{\partial t}+\frac{\partial F(U)}{\partial x}=S$

An improved erosion

model for surface

flows

S. He et al.

Title Page

Abstract

Conclusions

Tables

14

4

Back

Full Screen / Esc

Printer-friendly Version

Interactive Discussion 
in which,

$U=\left(\begin{array}{c}h \\ h u \\ h c\end{array}\right), \quad F(U)=\left(\begin{array}{c}h u \\ h u^{2}+\frac{1}{2} g h^{2} \\ h u c\end{array}\right)$,

GMDD

$S=\left(\begin{array}{c}\frac{E-D}{1-p} \\ u\left(z_{\mathrm{b}}\right) \frac{(E-D) \rho_{0}}{(1-p) \rho}-g h\left(\frac{\partial z}{\partial x}+S_{f}\right)-\frac{\left(\rho_{s}-\rho_{w}\right) g h^{2}}{2 \rho} \frac{\partial c}{\partial x}-\frac{\left(\rho_{0}-\rho\right)(E-D) u}{\rho(1-p)} \\ E-D\end{array}\right)$.

An improved erosion

model for surface

flows

S. He et al.

5 The finite volume method is based on the integral form of the conservation Eq. (28). The discretization of the integral form ensures that the basic quantities, mass and momentum will also be conserved across a discontinuity. Fractional step method is used to solve the shallow water equation (SWE) numerically.

Step 1: Solve the homogeneous SWE

${ }_{10} \frac{\partial U}{\partial t}+\frac{\partial F(U)}{\partial x}=0$

A number of approximate Riemann solvers have been constructed to solve the Riemann problem in an efficient manner and Roe's approximation is one of them. In this paper the 1-D Riemann problem at the cell interface is solved using Roe's approximation. In Roe's approximation, the nonlinear problem is linearized at the cell interface. At the cell interface we have a discontinuity with state $U_{\mathrm{L}}$ on the left side and state $U_{R}$ on the right side. Equation (28) is linearized as follows

$$
\frac{\partial U}{\partial t}+\tilde{J} \frac{\partial U}{\partial x}=0
$$

Title Page

Abstract

Introduction

Conclusions

Tables

References

Figures

14

$\rightarrow$

4

Back

Close

Printer-friendly Version

Interactive Discussion 
where $\tilde{J}$ is the Roe-linearized normal Jacobian matrix of $F(U)$.

$\tilde{J}=\left[\begin{array}{ccc}0 & 1 & 0 \\ \tilde{m}^{2}-\tilde{u}^{2} & 2 u & 0 \\ -\tilde{u} \tilde{c} & \tilde{c} & \tilde{u}\end{array}\right]$

where $\tilde{h}=\sqrt{h_{\mathrm{R}} h_{\mathrm{L}}}, \tilde{u}=\frac{\sqrt{h_{\mathrm{R}}} u_{\mathrm{L}}}{\sqrt{h_{\mathrm{R}}}+\sqrt{h_{\mathrm{L}}}}, \tilde{c}=\frac{\sqrt{h_{\mathrm{R}}} c_{\mathrm{R}}+\sqrt{h_{\mathrm{L}}} c_{\mathrm{L}}}{\sqrt{h_{\mathrm{R}}}+\sqrt{h_{\mathrm{L}}}}, \tilde{m}=\sqrt{\frac{1}{2} g\left(h_{\mathrm{R}}+h_{\mathrm{L}}\right)}$.

5 Thus, the eigenvalues and the eigenvectors and the weighting factors have the same form as that given by Eqs. (31)-(33)

$\lambda_{1}=\tilde{u}-\tilde{m}, \quad \lambda_{2}=\tilde{u}, \quad \lambda_{3}=\tilde{u}+\tilde{m}$

$\gamma_{1}=\left[\begin{array}{c}1 \\ \tilde{u}-\tilde{m} \\ \tilde{c}\end{array}\right], \quad \gamma_{2}=\left[\begin{array}{l}0 \\ 0 \\ 1\end{array}\right], \quad \gamma_{3}=\left[\begin{array}{c}1 \\ \tilde{u}+\tilde{m} \\ \tilde{c}\end{array}\right]$

$\alpha_{1}=\frac{\left(h_{\mathrm{R}}-h_{\mathrm{L}}\right)}{2}-\frac{\tilde{h}\left(h_{\mathrm{R}}-h_{\mathrm{L}}\right)}{2 \tilde{m}} ; \quad \alpha_{2}=\tilde{h}\left(c_{\mathrm{R}}-c_{\mathrm{L}}\right) ; \quad \alpha_{3}=\frac{\left(h_{\mathrm{R}}-h_{\mathrm{L}}\right)}{2}+\frac{\tilde{h}\left(h_{\mathrm{R}}-h_{\mathrm{L}}\right)}{2 \tilde{m}}$

Once the cell interface problem has been linearized, it is a simple matter to compute the normal flux $F_{i}$.

$F_{i+\frac{1}{2}}=\frac{1}{2}\left(F_{i}+F_{i+1}\right)-\frac{1}{2} \sum_{j=1}^{2} \alpha_{j}\left|\lambda_{j}\right| \gamma_{j}$

15 So that, the expression for the numerical scheme is

$U_{i}^{*}=U_{i}^{n}+\frac{\mathrm{d} t}{\mathrm{~d} x}\left(F_{i-\frac{1}{2}}-F_{i+\frac{1}{2}}\right)$

An improved erosion

model for surface

flows

S. He et al.

Title Page

Abstract

Introduction

Conclusions

References

Tables

Figures

14

$\rightarrow$

4

Back

Close

Full Screen / Esc

Printer-friendly Version

Interactive Discussion 
After we solve the homogeneous SWE, the conservation law of the sediment can be calculated as the first step.

$\left(Z_{\mathrm{b}}\right)_{i}^{*}=\left(Z_{\mathrm{b}}\right)_{i}^{n}-\frac{E_{i}^{n}-D_{i}^{n}}{1-p}$

5 Step 2: Solve the source term

$\frac{\partial U}{\partial t}=S$

To reduce numerical instabilities, we adopt the semi-implicit method and the equations are discretized as below:

${ }_{10} \frac{U_{i}^{n+1}-U_{i}^{*}}{\Delta t}=S_{i}^{*}$

where $U_{i}^{*}, S_{i}^{*}$ are solutions of Step 1.

With the $U_{i}^{n+1}$, we can calculate the conservation law of the sediment as the second step.

${ }_{15}\left(Z_{\mathrm{b}}\right)_{i}^{n+1}=\left(Z_{\mathrm{b}}\right)_{i}^{*}-\frac{E_{i}^{n}-D_{i}^{n}}{1-p}$

where $E_{i}^{n+1}, D_{i}^{n+1}$ can be solved with $U_{i}^{n+1}$.

The stability criterion adopted here is expressed by

$\Delta t \leq \min \left(\frac{\mathrm{CFL} \times \Delta x}{\max (|u|+m)}\right)$

Printer-friendly Version

where $\mathrm{CFL}(\leq 1)$ is Courant number, $m=\sqrt{g h}, \Delta x$ is the distance between the centroid of the cell.

An improved erosion

model for surface

flows

S. He et al.

Title Page

Abstract

Introduction

Conclusions

References

Tables

Figures

14

$\rightarrow 1$

$\triangleleft$

Back

Close

Full Screen / Esc

Interactive Discussion

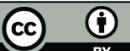




\section{Numerical tests}

In order to verify the stability of the algorithm and reliability of the numerical results, a classical test case was performed. In this paper, we use the 1-D dam-break problem with an erodible sediment flat bottom. Such dam break problem has been adopted 5 to verify shock-capturing capacity and used extensively by many authors after an analytical solution was proposed by Stoker (1957). Figure 2 shows a schematic diagram of the problem, in this problem we set that the channel length $x=200 \mathrm{~m}$ and the dam is located at the middle of it $(x=100 \mathrm{~m})$. The water depths on both sides of dam include upstream and downstream are $h_{1}=10 \mathrm{~m}$ and $h_{2}=2 \mathrm{~m}$ respectively.

10 The channel bed is composed of non-cohesive uniform sediment and the initial height $z=0 \mathrm{~m}$. The computational parameters are listed in Table 2.

As discussed above, the previous models which used non-sliding boundary condition and neglected the entrainment and deposition effect on the momentum equation underestimate the dam-break flow erosion ability and mobility. In reality, due to water 15 erosion, the bottom boundary velocity is not zero (Iverson, 2012, 2013; Le and Pitman, 2009), and can be expressed as: $0 \leq u\left(z_{\mathrm{b}}\right) \leq \bar{u}$. So comparisons of the model proposed in this paper $\left(u\left(z_{\mathrm{b}}\right)=\bar{u}\right)$ and that proposed by CAO $\left(u\left(z_{\mathrm{b}}\right)=0\right)$ are done with the problem of one dimension dam-break over an erodible bed. Figure 3 shows the water depth variations along the channel for a dam-break flow over an erodible bed at time be expected, the erosion depth, volume fraction of solid in the model proposed in this paper is larger than that in Cao's model, which indicates the erosion can strength the flow and exhibit more erosion ability.

To study the influence of velocity in the bed on the erosion, the three cases with different velocity in bed $(0.25 \bar{u}, 0.5 \bar{u}, 0.75 \bar{u})$ are preformed, and the results is shown in Fig. 4. As shown in the figure, the larger the velocity in the bed, the greater the mobility and erosion ability of the flow occurrence. Figure 5 shows the relationship between the maximum erosion depth and the velocity in the bed at different times $(t=4,6$, and
GMDD

7, 2429-2454, 2014

An improved erosion model for surface flows

S. He et al.

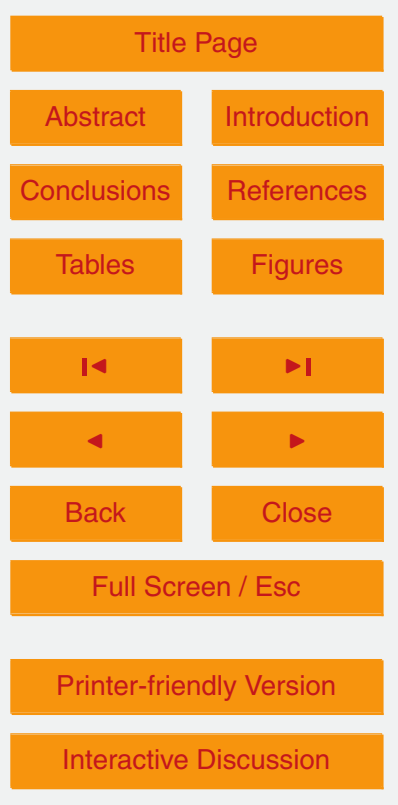

Interactive Discussion 
$8 \mathrm{~s})$. It can be seen that the relationship between the maximum erosion depth and the velocity in the bed is almost linear.

\section{Conclusions}

This paper presents a new coupled model of water flow, sediment transport and bed 5 evolution based on the shallow water assumption, depth-average integration as well as the morphological evolution. Compared to the previous models, the present model takes account of the effects of rainfall, entrainment and deposition on the motion of the water-sediment mixture. In this model we perform numerical simulation by the finite volume method and the Roe's approximate Riemann solver has been adopted. 10 The results has been simulated are compared with the model of Cao et al. (2004) . Potential model to verify the veracity of our model and the feasibility of applying our model to some events such as channel development caused by rainfall, sediment transport caused by tsunami and/or floods.

One of the most important advantages that the formulation presented in this paper offers over many existing models is that the influence of the entrainment and deposition on momentum equation are considered. The one-dimensional dam-break problem is performed to validate the model. Comparisons are done with the model by Cao et al. (2004), and the influence of the velocity in bed on the erosion is analyzed. Through the analysis of numerical solutions simulated according to the actual scales and some

(1) The entrainment and deposition can enhance the mobility and erosion ability of water flow.

(2) The influence of the velocity in the bed on the erosion is important, with increasing of the velocity in bed, the depth of erosion, the volume fraction of solid, and the flow depth increase significantly.
GMDD

7, 2429-2454, 2014

An improved erosion model for surface flows

S. He et al.

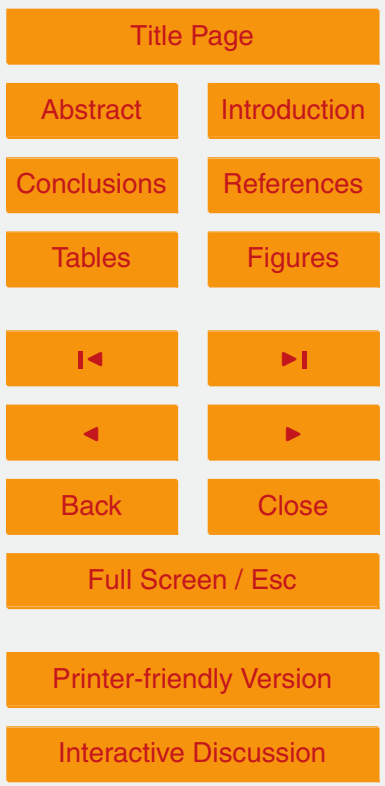


(3) The relationship between the maximum erosion depth and the velocity in the bed is almost a linear one.

\section{Code availability}

A Matlab based function is provided to illustrate the presented model. This simple 5 function is programmed only for the examples in the paper. The code has been uploaded with this submission and can also be obtained by contact Wei Liu (sponlol@163.com).

\section{Supplementary material related to this article is available online at http://www.geosci-model-dev-discuss.net/7/2429/2014/ \\ 10 gmdd-7-2429-2014-supplement.zip.}

Acknowledgements. We acknowledge the financial support from the National Key Basic Research Program of China (Project No. 2013CB733201), NSFC (Grant No. 41272346, 41101008), and the Key Research Program of the Chinese Academy of Sciences (KZZD-EW05-01).

\section{References}

Benkhaldoun, F., Sahmim, S., and Seaid, M.: A two-dimensional finite volume morphodynamic model on unstructured triangular grids, Int. J. Numer. Meth. Fl., 63, 1296-1327, doi:10.1002/fld.2129, 2011.

Benkhaldoun, F., Sari, S., and Seaid, M.: A flux-limiter method for dam-break flows over erodible sediment beds, Applied Mathematical Modelling, 36, 4847-4861, doi:10.1016/j.apm.2011.11.088, 2012.

An improved erosion

model for surface

flows

S. He et al.

Title Page

Abstract

Introduction

Conclusions

Tables

References

Figures

14

$\triangleleft$

Back

Close

Printer-friendly Version

Interactive Discussion 
Cao, Z., Pender, G., Wallis, S., and Carling, P.: Computational dam-break hydraulics over erodible sediment bed, J. Hydraul. Eng., 130, 689-703, doi:10.1061/(ASCE)07339429(2004)130:7(689), 2004.

Cao, Z., Gareth, P., and Paul, C.: Shallow water hydrodynamic models for hypercon5 centrated sediment-laden floods over erodible bed, Adv. Water Resour., 29, 546-557, doi:10.1016/j.advwatres.2005.06.011, 2006.

Fagherazzi, S. and Sun, T.: Numerical simulations of transportational cyclic steps, Comput. Geosci., 29, 1143-1154, doi:10.1016/S0098-3004(03)00133-X, 2003.

Fraccarollo, L. and Capart, H.: Riemann wave description of erosional dam-break flows, J. Fluid Mech., 461, 183-228, doi:10.1017/S0022112002008455, 2002.

Gray, J. M. N. T.: Granular flow in partially filled slowly rotating drums, J. Fluid Mech., 441, 1-29, doi:10.1017/S0022112001004736, 2001.

$\mathrm{Hu}, \mathrm{P}$. and Cao, Z.: Fully coupled mathematical modeling of turbidity currents over erodible bed, Adv. Water Resour., 32, 1-15, doi:10.1016/j.advwatres.2008.07.018, 2009.

Iverson, R. M.: Elementary theory of bed-sediment entrainment by debris flows and avalanches, J. Geophys. Res., 117, F03006, doi:10.1029/2011JF002189, 2012.

Iverson, R. M. and Ouyang, C.: Bed-sediment entrainment by rapidly evolving flows at Earth's surface: 1 review and reformulation of depth-integrated theory, Rev. Geophys., submitted, 2013

$20 \mathrm{Li}$, S. and Duffy, C. J.: Fully coupled approach to modeling shallow water flow, sediment transport, and bed evolution in rivers, Water Resour. Res., 47, W03508, doi:10.1029/2010WR009751, 2011.

Le, L. and Pitman, E. B.: A model for granular flows over an erodible surface, SIAM J. Appl. Math., 70, 1407-1427, doi:10.1137/060677501, 2009.

Murillo, J. and García-Navarr, P.: An Exner-based coupled model for two-dimensional transient flow over erodible bed, J. Comput. Phys., 229, 8704-873, doi:10.1016/j.jcp.2010.08.006, 2010.

Pitman, E. B. and Le, L.: A two-fluid model for avalanche and debris flows, Philos. T. Roy. Soc. A, 363, 1573-1602, doi:10.1098/rsta.2005.1596, 2005.

30 Savage, S. B. and Hutter, K.: The motion of a finite mass of granular material down a rough incline, J. Fluid Mech., 199, 177-21, doi:10.1017/S0022112089000340, 1989.

Schippa, L. and Pavan, S.: Bed evolution numerical model for rapidly varying flow in natural streams, Comput. Geosci., 35, 390-40, doi:10.1016/j.cageo.2008.08.004, 2009.

An improved erosion model for surface flows

S. He et al.

Title Page

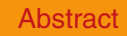

Introduction

Conclusions

Tables

References

Figures

14

$\triangleleft$

Back

Close

Printer-friendly Version

Interactive Discussion 
Simpson, G. and Castelltort, S.: Coupled model of surface water flow, sediment transport and morphological evolution, Comput. Geosci., 32, 1600-1614, doi:10.1016/j.cageo.2006.02.020, 2006.

Stocker, J. J.: Water Waves, the Mathematical Theory with Applications, Wiley Interscience, New York, 1957.

Tassi, P. A., Rhebergen, S., Vionnet, C. A., and Bokhove, O.: A discontinuous Galerkin finite element model for river bed evolution under shallow flows, Comput. Method. Appl. M., 197, 2930-2947, doi:10.1016/j.cma.2008.01.023, 2008.

Xia, J., Lin, B., Falconer, R. A., and Wang, G.: Modelling dam-break flows over mobile beds using a 2-D coupled approach, Adv. Water Resour., 33, 171-18, doi:10.1016/j.advwatres.2009.11.004, 2010.

An improved erosion model for surface

flows

S. He et al.

Title Page

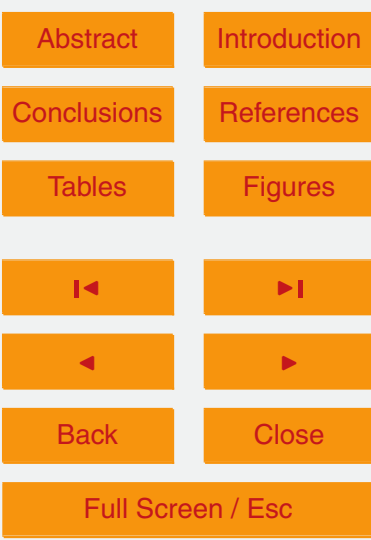

Printer-friendly Version

Interactive Discussion 
Table 1. Comparisons of other authors' conservation equation with Eq. (26) in this work.

GMDD

$7,2429-2454,2014$

\begin{tabular}{|c|c|c|}
\hline Authors & Conservation equation & Limitation \\
\hline $\begin{array}{l}\text { Cao et al. } \\
(2004,2006)\end{array}$ & 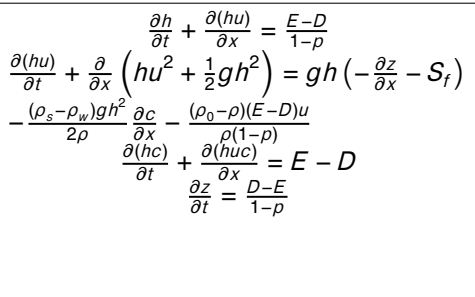 & $\begin{array}{l}\text { (1) One-dimension model } \\
\text { (2) Rainfall is not considered } \\
\text { (3) The effects of rainfall and entrain- } \\
\text { ment deposition, } u\left(z_{\mathrm{b}}\right)\left(\frac{(E-D) \rho_{0}}{1-P) \rho}-u\left(z_{\mathrm{t}}\right) R\right. \\
\text { are not considered in the momentum } \\
\text { equation. }\end{array}$ \\
\hline
\end{tabular}

\begin{tabular}{|c|c|c|}
\hline $\begin{array}{l}\text { Benkhaldoun } \\
\text { (2011) }\end{array}$ & 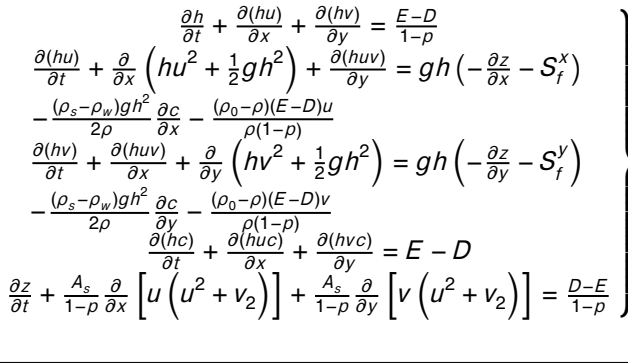 & $\begin{array}{l}\text { (1) Rainfall is not considered } \\
\text { (2) The effects of rainfall and en- } \\
\text { trainment deposition in } x \text { direction, } \\
u\left(z_{\mathrm{b}}\right) \frac{(E-D) \rho_{0}}{(1-\rho) \rho}-u\left(z_{\mathrm{t}}\right) R \text { and } y \text { direction, } \\
v\left(z_{\mathrm{b}}\right) \frac{(E-D) \rho_{0}}{(1-p) \rho}-v\left(z_{\mathrm{t}}\right) R \text { are not consid- } \\
\text { ered in the momentum equations. }\end{array}$ \\
\hline $\begin{array}{l}\text { Simpson } \\
(2006)\end{array}$ & $\begin{array}{c}\frac{\partial h}{\partial t}+\frac{\partial(h u)}{\partial x}+\frac{\partial(h v)}{\partial y}=\alpha+\frac{E-D}{1-p} \\
\frac{\partial(h u)}{\partial t}+\frac{\partial}{\partial x}\left(h u^{2}+\frac{1}{2} g h^{2}\right)+\frac{\partial(h u v)}{\partial y}=g h\left(-\frac{\partial z}{\partial x}-S_{f}^{x}\right) \\
+\varepsilon\left[\frac{\partial^{2}(h u)}{\partial^{2} x}+\frac{\partial^{2}(h u)}{\partial \partial^{2} y}\right]-\frac{\left(\rho_{s}-\rho_{w}\right) g h^{2}}{2 \rho} \frac{\partial c}{\partial x}-\frac{\left(\rho_{0}-\rho\right)(E-D) u}{\rho(1-D)} \\
\frac{\partial(h v)}{\partial t}+\frac{\partial(h h v)}{\partial x}+\frac{\partial}{\partial y}\left(h v^{2}+\frac{1}{2} g h^{2}\right)=g h\left(-\frac{\partial z}{\partial y}-S_{f}^{y}\right) \\
+\varepsilon\left[\frac{\partial^{2}(h v)}{\partial^{2} x}+\frac{\partial^{2}(h h)}{\left(\partial^{2} y\right.}\right]-\frac{\left(\rho_{s}-\rho_{w}\right) g h^{2}}{2 \rho} \frac{\partial c}{\partial y}-\frac{\left(\rho_{0}-\rho\right)(E-D) v}{\rho(1-D)} \\
\frac{\partial(h)}{\partial t}+\frac{\partial(h u c)}{\partial x}+\frac{\partial(h v)}{\partial y}=E-D \\
\frac{\partial z}{\partial t}=\frac{D-E}{1-p}\end{array}$ & $\begin{array}{l}\text { The effects of entrainment and de- } \\
\text { position in } x \text { direction, } u\left(z_{\mathrm{b}}\right) \frac{(E-D) \rho_{0}}{(1-p) \rho}- \\
u\left(z_{\mathrm{t}}\right) R \text { and } y \text { direction, } v\left(z_{\mathrm{b}}\right) \frac{(E-D) \rho_{0}}{(1-P) \rho}- \\
v\left(z_{\mathrm{t}}\right) R \text { are not considered in the } \\
\text { momentum equations. }\end{array}$ \\
\hline
\end{tabular}

An improved erosion model for surface flows

S. He et al.

Title Page

Abstract

Conclusions

Tables

14

4

Back
Introduction

References

Figures

I

$>$

Close

\section{Full Screen / Esc}

Printer-friendly Version

Interactive Discussion 
Table 2. Computational parameters of dam-break over erodible bed.

\begin{tabular}{lccccccccc}
\hline Coefficients & $n$ & $\begin{array}{c}d \\
(\mathrm{~mm})\end{array}$ & $\begin{array}{c}\rho_{\mathrm{s}} \\
\left(\mathrm{kg} \mathrm{m}^{-3}\right)\end{array}$ & $\begin{array}{c}\rho_{\mathrm{w}} \\
\left(\mathrm{kg} \mathrm{m}^{-3}\right)\end{array}$ & $m$ & 0 & $p$ & $\phi$ & $\theta_{\mathrm{c}}$ \\
\hline Values & 0.03 & 8 & 2840 & 1000 & 2 & $1.2 \times 10^{-6}$ & 0.4 & 0.015 & 0.045 \\
\hline
\end{tabular}

An improved erosion model for surface flows

S. He et al.

Title Page

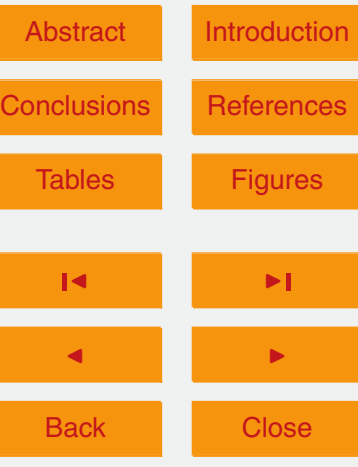

Full Screen / Esc

Printer-friendly Version

Interactive Discussion

(c) 


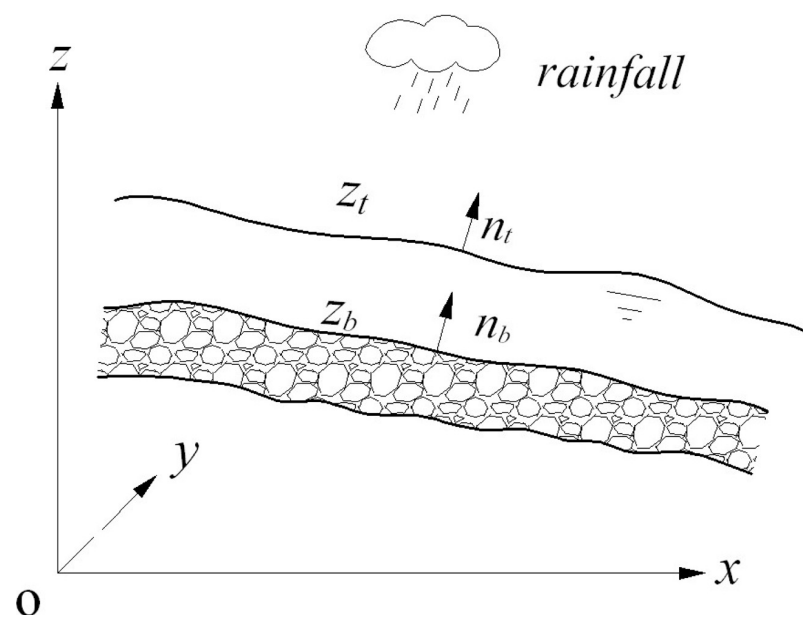

Fig. 1. Schematic depictions of a moving sediment-water layer that can exchange mass and momentum with a static bed layer under rainfall.

\section{GMDD}

$7,2429-2454,2014$

An improved erosion model for surface

flows

S. He et al.

Title Page

Abstract

Introduction

Conclusions

References

Tables

Figures

14

$\rightarrow$

4

Back

Close

Full Screen / Esc

Printer-friendly Version

Interactive Discussion 


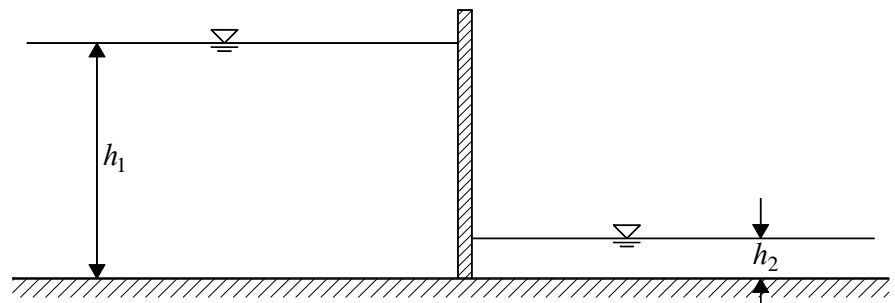

\section{GMDD}

7, 2429-2454, 2014

An improved erosion model for surface flows

S. He et al.

Title Page

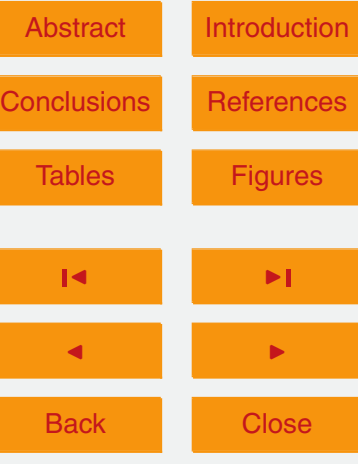

Full Screen / Esc

Printer-friendly Version

Interactive Discussion 

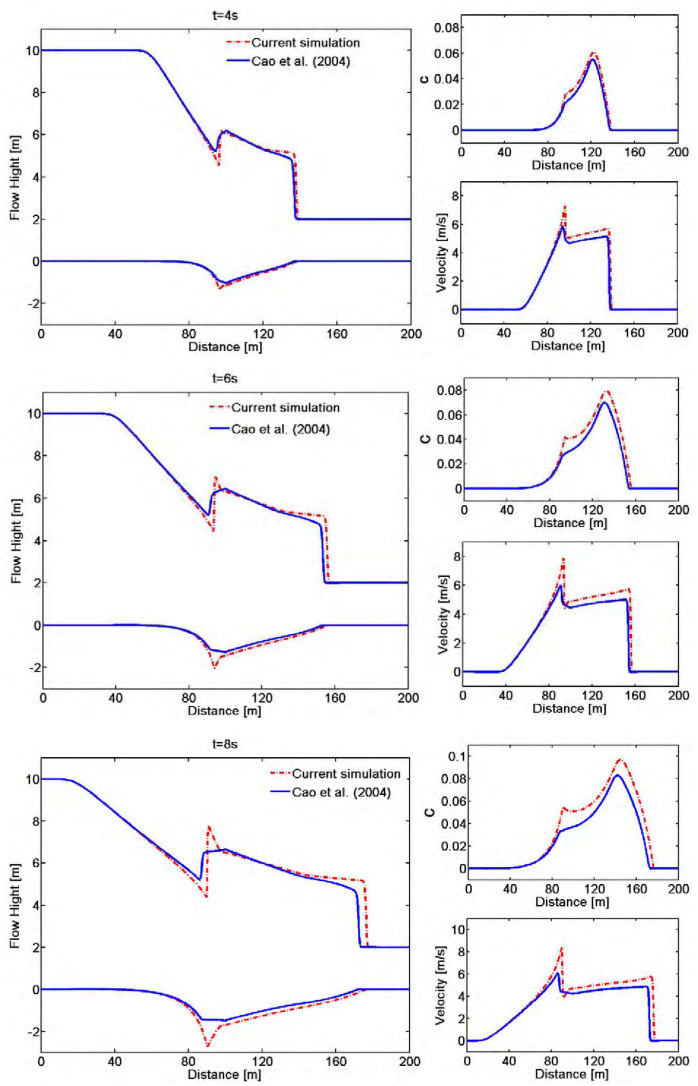

Fig. 3. The profiles of free surface, erodible bed, volume fraction of solid $C$ and flow velocity at time $t=4,6$, and $8 \mathrm{~s}$, respectively. Comparisons of current model results with that of Cao et al. (2004).

\section{GMDD}

7, 2429-2454, 2014

An improved erosion model for surface

flows

\section{S. He et al.}

\section{Title Page}

\section{Full Screen / Esc}

Printer-friendly Version

Interactive Discussion 

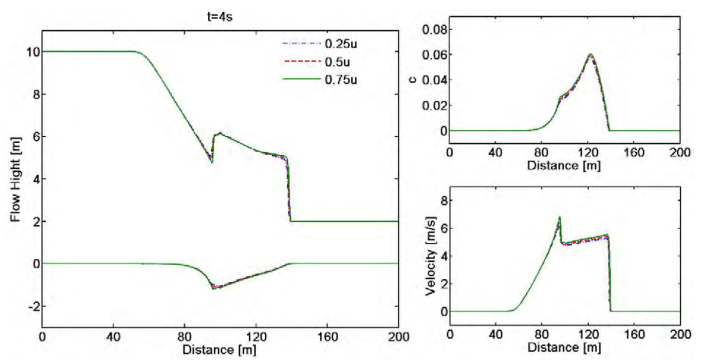

GMDD

7, 2429-2454, 2014

An improved erosion model for surface flows

S. He et al.
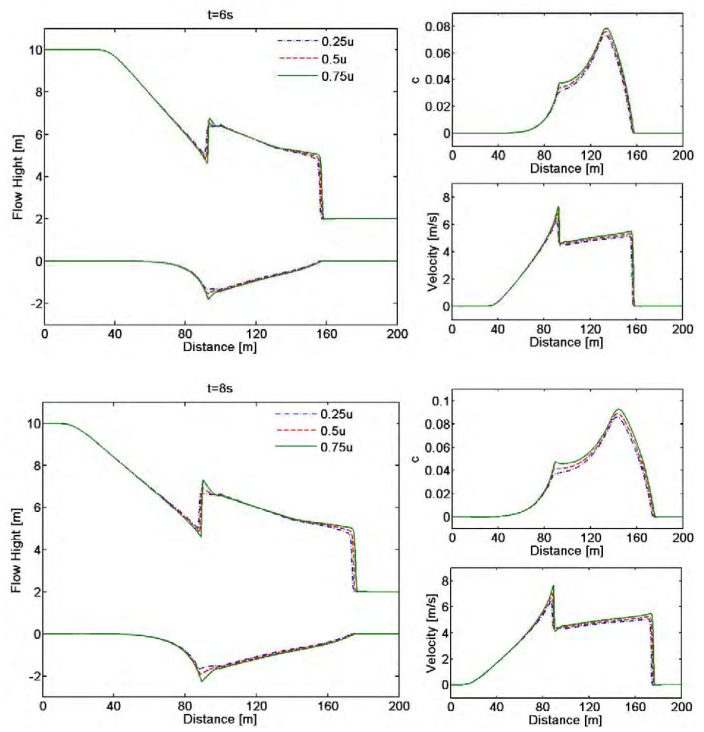

Fig. 4. Comparison of results of 1-D dam-break over an erodible bed with different velocity in the bed.

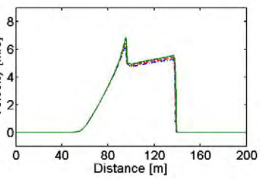

Title Page

Abstract

Introduction

Conclusions

References

Tables

Figures

14

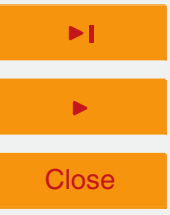

Back

Full Screen / Esc

Printer-friendly Version

Interactive Discussion 


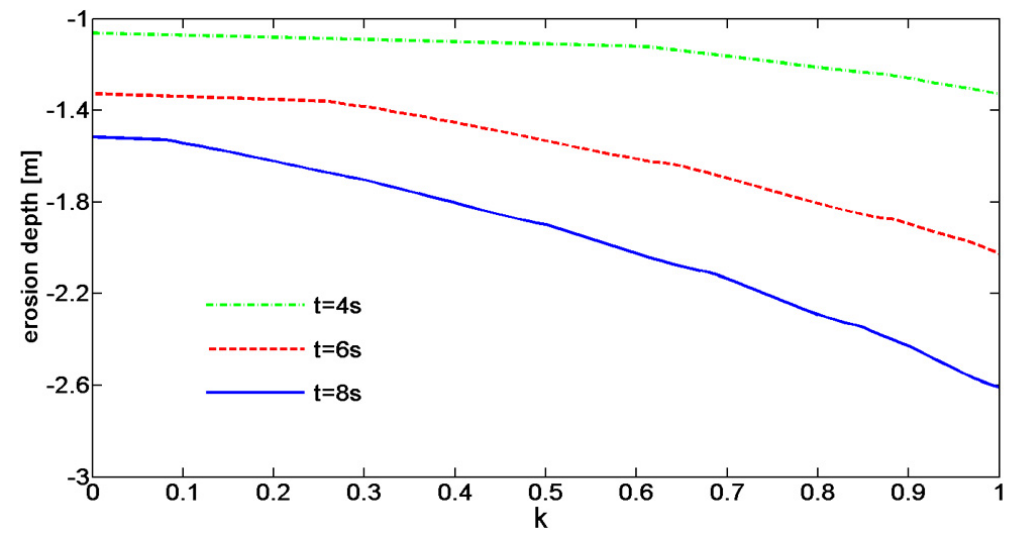

Fig. 5. The relationship between the maximum depth of erosion and the velocity in the bed.

\section{GMDD}

$7,2429-2454,2014$

An improved erosion model for surface flows

S. He et al.

Title Page

Abstract

Introduction

Conclusions

References

Tables

Figures

14

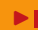

4

Back

Close

Full Screen / Esc

Printer-friendly Version

Interactive Discussion 